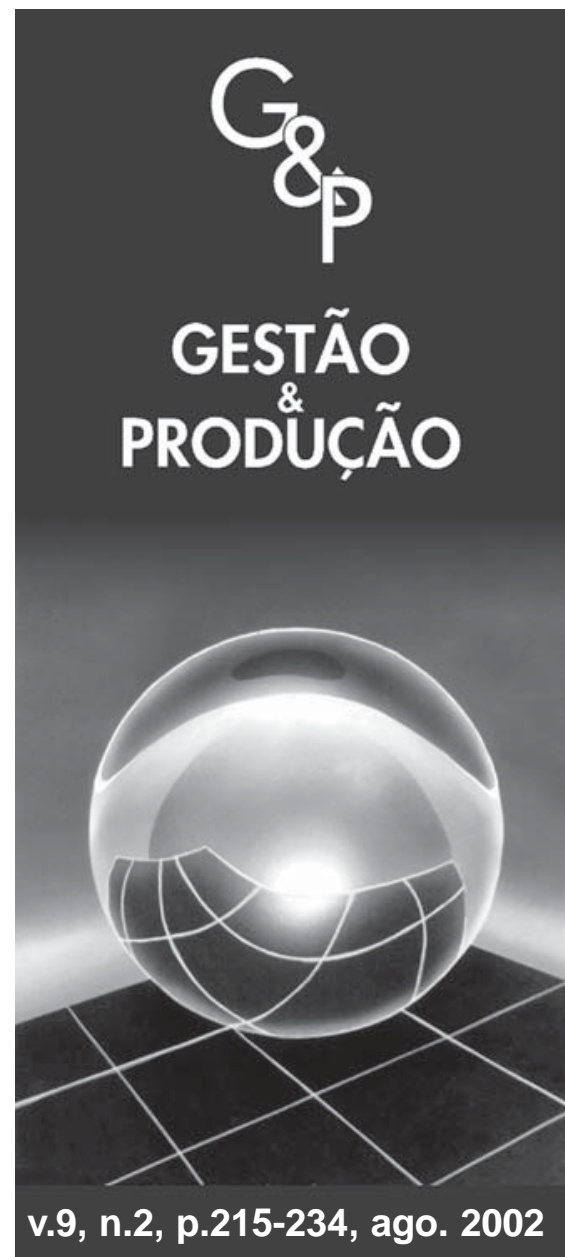

\title{
A INTERDEPENDÊNCIA ENTRE SISTEMAS DE CONTROLE DE PRODUÇÃO E CRITÉRIOS DE ALOCAÇÃO DE CAPACIDADES
}

\author{
Fernando Bernardi de Souza \\ Faculdade de Engenharia Mecânica e de Produção, \\ Universidade Metodista de Piracicaba, \\ e-mail: fbsouza@unimep.br \\ Antonio Freitas Rentes \\ Oswaldo Luiz Agostinho \\ Departamento de Engenharia de Produção, \\ EESC/Universidade de São Paulo, \\ e-mail: rentes@sc.usp.br, \\ oswaldolagostinho@eaton.com
}

\section{Resumo}

Há uma aparente carência de pesquisas sobre os inter-relacionamentos entre critérios de alocação de capacidades de recursos de manufatura e os métodos de controle de produção. Estudos sobre alocação de capacidades se baseiam geralmente em sistemas simplificados de empurrar a produção, desconsiderando sistemas mais atuais de gestão de produção. Por outro lado, pesquisas sobre a aplicabilidade de sistemas de gestão da produção não consideram apropriada a maneira como as capacidades produtivas dos recursos estão alocadas ao longo da linha. Analisar as interdependências entre esses dois grandes ramos de pesquisa é o objetivo deste artigo.

Palavras-chave: alocação de capacidades, balanceamento, desbalanceamento, Kanban, CONWIP, tambor-pulmão-corda.

\section{Introdução}

Há uma percepção quase generalizada nos meios acadêmicos e empresariais de que a melhor maneira de alocar capacidades produtivas entre recursos fabris de uma linha de manufatura é aquela em que todas as estações de trabalho recebem a mesma quantidade de carga imposta pela demanda de mercado, ou seja, seus recursos estão balanceados (Hillier \& Boling, 1966; Fry \& Russell, 1993; Atwater \& Chakravorty, 1994; Goldratt \& Cox, 1995). 
Diversos pesquisadores, no entanto, vêm estudando novas maneiras de distribuir tempos de tarefas como meio de melhorar a eficiência de linhas de produção, como Davis (1966), Hillier \& Boling (1966), Payne et al. (1972), El-rayah (1979a), Goldratt (1981), Sarker (1984), Smunt \& Perkins (1985), So (1989), Fry \& Russell (1993), Pike \& Martin (1994), Chakravorty \& Atwater (1996), dentre outros. Tais pesquisas se baseiam, em geral, em sistemas produtivos com as seguintes características: a) o primeiro recurso tem sempre material disponível para trabalhar, b) há quantidade pré-fixada (finita ou infinita) de capacidade de armazenagem de materiais entre os recursos e c) o material é empurrado pela linha de produção até que o último recurso o processe e o libere na forma de produto acabado. Segundo esses estudos, a produção de cada recurso pode ser interrompida normalmente por dois motivos: falta de material para processar ou bloqueio devido à presença de um pulmão de armazenagem no nível máximo a sua frente. O último recurso nunca fica bloqueado. Esse tipo de sistema de gestão da manufatura é denominado aqui de sistema ROP (Reorder Point).

Por outro lado, muitos estudos têm buscado qual sistema de controle da produção (PCP) é melhor para situações genéricas ou particulares. Diversas formulações desenvolvidas parecem indicar não haver um tipo de sistema melhor que responda a todas as situações, devendo a escolha ser decidida caso a caso (veja, por exemplo, Aggarwal (1985), Ramsay et al. (1990), Burbidge (1990), Spearman et al. (1990), Newman \& Sridharan (1992), Ptak (1991), Cook (1994), Gstettner \& Kuhn (1996), Miltenburg (1997) e Huang \& Kusiak (1998). Entretanto, um aspecto parece não ter sido considerado devidamente durante a análise de determinado sistema de PCP: em que tipo de projeto de linha o sistema de PCP foi avaliado? Balanceado ou desbalanceado? Este artigo mostrará que tais aspectos são de alta relevância no desempenho dos sistemas de controle e, portanto, deveriam ser considerados de maneira especial.

Da mesma forma, em sentido contrário, este artigo também procurará mostrar até que ponto as diferentes configurações de linhas influenciam no desempenho dos sistemas de PCP.

\section{Objetivo do trabalho}

O objetivo deste trabalho é estudar a eficiência de oito configurações de distribuições de capacidades entre recursos segundo quatro métodos de gestão da produção. As oito configurações e os quatro métodos em questão são os mais freqüentemente apresentados na literatura técnica. São eles:

1. Distribuição balanceada.

2. Distribuição Bowl, Hillier \& Boling (1966).

3. Distribuição linear crescente, Davis (1966).

4. Distribuição linear decrescente, Fry \& Russell (1993) e Davis (1966);

5. Distribuição segmentada, FRY \& Russell (1993) e Goldratt (1981).

6. Distribuição em passo, Fry \& Russell (1993) e Wight (1970).

7. Distribuição em “V”, Fry \& Russell (1993).

8. Distribuição alternada, Patterson (1964).

A Tabela 1 ajuda a entender os critérios distributivos de capacidade sugeridos pelas oito configurações aqui estudadas. Os quatro métodos de gestão da produção aqui abordados são:

1. Sistema Reorder Point (ROP)

2. Sistema de controle Kanban tradicional

3. Sistema CONWIP básico

4. Sistema tambor-pulmão-corda (TPC) 
Tabela 1 - Tempos médios de processamento propostos para pesquisa.

\begin{tabular}{|c|c|c|c|c|c|}
\hline Configuração (forma) & Recurso 1 & Recurso 2 & Recurso 3 & Recurso 4 & Recurso 5 \\
\hline Balanceado & 1,000 & 1,000 & 1,000 & 1,000 & 1,000 \\
\hline Bowl GD (alt) & 1,176 & 0,890 & 0,868 & 0,890 & 1,176 \\
\hline Bowl GD (méd) & 1,100 & 0,938 & 0,924 & 0,938 & 1,100 \\
\hline Bowl GD (bxo) & 1,025 & 0,985 & 0,980 & 0,985 & 1,025 \\
\hline V GD (alt) & 0,824 & 1,102 & 1,148 & 1,102 & 0,824 \\
\hline V GD (méd) & 0,900 & 1,059 & 1,082 & 1,059 & 0,900 \\
\hline V GD (bxo) & 0,975 & 1,015 & 1,020 & 1,015 & 0,975 \\
\hline Linear cresc. GD (alt) & 1,235 & 1,117 & 1,000 & 0,883 & 0,765 \\
\hline Linear cresc. GD (méd) & 1,133 & 1,067 & 1,000 & 0,933 & 0,867 \\
\hline Linear cresc. GD (bxo) & 1,033 & 1,017 & 1,000 & 0,983 & 0,967 \\
\hline Linear decresc. GD (alt) & 0,765 & 0,883 & 1,000 & 1,117 & 1,235 \\
\hline Linear decresc. GD (méd) & 0,867 & 0,933 & 1,000 & 1,067 & 1,133 \\
\hline Linear decresc. GD (bxo) & 0,967 & 0,983 & 1,000 & 1,017 & 1,033 \\
\hline Segmentado GD (alt) & 1,044 & 0,824 & 1,264 & 1,044 & 0,824 \\
\hline Segmentado GD (méd) & 1,025 & 0,900 & 1,150 & 1,025 & 0,900 \\
\hline Segmentado GD (bxo) & 1,006 & 0,975 & 1,038 & 1,006 & 0,975 \\
\hline Step GD (alt) & 1,352 & 0,912 & 0,912 & 0,912 & 0,912 \\
\hline Step GD (méd) & 1,200 & 0,950 & 0,950 & 0,950 & 0,950 \\
\hline Step GD (bxo) & 1,050 & 0,9875 & 0,9875 & 0,9875 & 0,9875 \\
\hline Mix GD (alt) & 0,824 & 1,176 & 0,824 & 1,176 & 1,000 \\
\hline Mix GD (méd) & 0,900 & 1,100 & 0,900 & 1,100 & 1,000 \\
\hline Mix GD (bxo) & 0,975 & 1,025 & 0,975 & 1,025 & 1,000 \\
\hline
\end{tabular}

Como medida de eficiência das linhas de produção, foi selecionada como variável de interesse a taxa média de produção ou throughput, simbolizada por OP ao longo do texto, em função de três parâmetros básicos:
1. Níveis médios e máximos de estoque em processo na linha (WIP médio e WIP máximo).

2. Nível de variabilidade dos tempos de processamento dos recursos. 
3. Grau de desbalanceamento dos recursos da linha.

O objetivo deste trabalho foi identificar o nível de influência que as diversas alocações de capacidades têm sobre certos sistemas de controle da produção, assim como analisar de que forma os sistemas de controle da produção influenciam no desempenho de alguns critérios de distribuição de capacidades produtivas entre recursos em uma linha de manufatura.

Com o propósito de permitir modelar e estudar as diversas situações resultantes desses cruzamentos, optou-se pela simulação como método mais adequado para desenvolvimento desta pesquisa. Foi utilizado para este fim o software GPSS/H, da companhia Wolverine Software Corporation. A seguir apresenta-se um breve resumo dos métodos de alocação de capacidades e, posteriormente, dos sistemas de gestão da produção selecionados para esta pesquisa.

\section{Os métodos de alocação de capacidades entre recursos de manufatura}

Pesquisas sobre linhas de produção remontam aos idos de 1962, quando Barten (1962) procurou determinar, via simulação, os níveis ótimos de estoque em processo para linhas de montagens com tempos de tarefas estocásticos. A partir daí, várias pesquisas sobre linhas de montagem foram conduzidas, tanto por abordagens analíticas quanto por simulação, a fim de estudar diversos critérios para alocação de capacidades de estocagem entre recursos e alocação de tempos de tarefas aos recursos.

Hillier \& Boling (1966) estabeleceram um verdadeiro marco na pesquisa sobre a questão do desbalanceamento de linhas de produção. Suas descobertas, genericamente conhecidas como "fenômeno bowl", foram e continuam sendo base de pesquisa para diversos outros estudos sobre o tema. Segundo os autores, a taxa de produção para sistemas com três ou mais estações é maximizada alocando-se menos tempo de processamento médio nas estações intermediárias em comparação com as estações localizadas no extremo da linha. A isto os autores chamam de fenômeno bowl. Outros estudos deram sequiência a este trabalho, dentre eles Hillier \& Boling (1979), So (1989) e Hillier \& So (1993).

O fenômeno bowl não pode, entretanto, ser considerado a melhor forma de alocar cargas em elementos produtivos de uma linha. Além de a eficiência do fenômeno bowl ter sido contestada em vários trabalhos (Smunt \& Perkins, 1985; Thompson Junior \& Burford, 1988), há também na literatura outras propostas de distribuição de capacidades de produção.

Para Davis (1966), por exemplo, parece haver algum ganho quando se tem uma linha desbalanceada com o primeiro recurso tendo o menor tempo médio de processamento (recurso rápido) e o último recurso, o maior tempo médio de processamento (recurso lento).

Outra proposta para desbalanceamento de linha foi feita por Patterson (1964). Ele desenvolveu um método para computar a taxa de produção da linha de determinado arranjo de recursos no sistema. Ainda que o autor não tenha sido capaz de determinar qual o arranjo ótimo de recursos, ele especulou quais recursos rápidos (pequenos tempos médios de serviço) e lentos (altos tempos médios de serviço) devem ser alternados para que se minimizem os efeitos de bloqueio dentro do sistema.

Payne et al. (1972) também fizeram uma importante contribuição para o entendimento dos fundamentos de uma linha de produção, confirmando, particularmente, alguns resultados obtidos em Davis (1966).

Outra interessante pesquisa se deu em Fry \& Russell (1993). Em estudo comparativo de diferentes formas de alocação de cargas entre os recursos, os autores comparam seis tipos de critérios de distribuição de cargas de trabalho entre recursos de uma fábrica fictícia que compartilha características tanto de um sistema flow-shop quanto de um sistema job-shop. Os seis critérios testados foram: balanceado, em forma de tigela (bowl), tigela invertida ou "V", linear (Davis, 1966; El-rayah, 1979a; Goldratt \& Fox, 1989), em passo ou step (Wight, 1970) e 
segmentado (Goldratt, 1981). Em suas pesquisas, os autores avaliaram cada um dos critérios citados segundo três formatos de alocação de carga (mais acentuado, moderado e pouco acentuado), três níveis de excesso de capacidade $(10 \%, 15 \%$ e $20 \%)$ e dois níveis de variabilidade (alto e baixo).

\section{Os sistemas de gestão da produção}

Serão considerados neste trabalho quatro sistemas de gestão da produção, todos se diferenciando pela maneira como controlam seus estoques. $\mathrm{O}$ primeiro deles, aqui denominado Reorder Point (ROP), já foi definido anteriormente. O segundo sistema a ser analisado é o Kanban, que faz parte de uma filosofia mais ampla de administração desenvolvida pela Toyota Motor Corporation, denominada Sistema de Produção da Toyota. Por intermédio desse sistema a produção de um recurso é disparada segundo a necessidade de peças do recurso que o procede. Dessa forma, partindo-se das necessidades da demanda final, todo o processo produtivo é "puxado" até que se alcance as necessidades de produção do primeiro recurso fabril. Para viabilizar esse tipo de sistema, cartões tipo Kanban são utilizados, os quais determinam um lote de peças para cada item do mix de produção da fábrica. Em Monden (1984), Ptak (1991), Berkley (1991) e Takahashi et al. (1996) pode-se encontrar mais detalhes dos mecanismos de funcionamento desse sistema.

O sistema CONWIP (Spearman et al., 1990) é uma forma mais específica de Kanban, já que também é baseado em sinais. Entretanto, no CONWIP, os cartões realizam um circuito que inclui a linha de produção inteira. Para tanto, um cartão é fixado em um contêiner-padrão de peças no início da linha. Há um número predefinido de cartões que define uma quantidade fixa e constante de estoques (CONstant WIP) para a linha. Quando um contêiner é usado no final da linha, o cartão é removido e enviado de volta para o início, onde ele espera na fila de cartões para eventualmente ser fixado em outro contêiner de peças.
Enquanto no sistema Kanban cada cartão é usado para sinalizar a produção de uma peça específica, no CONWIP os cartões são designados para toda a linha de produção e não correspondem a uma peça específica. A necessidade específica de uma peça é determinada segundo uma lista (backlog) de itens demandados. Quando o trabalho é necessário ao primeiro centro de processamento da linha, um cartão é removido da fila e marcado com o primeiro tipo de peça da lista para o qual matéria-prima ou componentes estão presentes.

O quarto e último sistema de gestão da produção aqui estudado é o tambor-pulmão-corda (TPC) baseado na Teoria das Restrições (Goldratt, 1995). Este método reconhece que há poucos recursos com restrição de capacidade (RRCs) que irão impor o índice de produção da fábrica inteira (tambor). Para garantir que a produção desse recurso não seja interrompida por falta de peça, cria-se na frente dele um inventário que protegerá o ganho das vendas da fábrica contra a maioria das interrupções que possam ocorrer em um intervalo de tempo predeterminado (pulmão de tempo). Com o objetivo de impedir que haja aumento desnecessário nos níveis de estoque em processo, o material é liberado para a fábrica no mesmo ritmo com que o recurso restritivo o consome (corda), mas com defasagem no tempo equivalente ao pulmão de tempo estabelecido. Schragenheim \& Ronen (1990) discutem e exemplificam a aplicação da metodologia TPC.

\section{Definição do domínio de aplicação}

Os modelos a serem desenvolvidos se caracterizarão por:

a) Número de recursos: o modelo deverá conter cinco recursos. Conway et al. (1988) citam que a perda de capacidade ocorre nas primeiras cinco máquinas e que máquinas adicionais causam pouca perda adicional na capacidade da linha.

b) Tempos de processamento: a distribuição dos tempos de processamento configurará os oito tipos de distribuição de carga que serão estudados. Todas as linhas deverão 
ter o mesmo tempo de processamento total, ou seja, a soma dos tempos de processamento nos cinco recursos em todas as linhas deverá ser sempre mantida constante e igual a 5 .

c) Grau de desbalanceamento (GD): foram definidos três graus de desbalanceamento para a pesquisa, em que $\mathrm{GD}_{\text {(alt) }}$ corresponde ao nível mais alto de desbalanceamento, $\mathrm{GD}_{\text {(méd) }}$, ao nível médio de desbalanceamento, enquanto $\mathrm{GD}_{(\mathrm{bxo})}$ reflete linhas menos desbalanceadas. Para a escolha dos valores, foi utilizada uma abordagem fundamentada no trabalho de Hillier \& So, (1993), em que se pode encontrar algum insight para um arranjo que se aproxime do ótimo na alocação de cargas segundo a forma bowl. Uma vez calculados os tempos médios de processamento na distribuição bowl para os três níveis de intensidade de desbalanceamento, esses serviram de base para o cálculo dos tempos médios de processamento para as demais formas de alocação de cargas.

Dessa forma, foi confeccionada uma tabela (Tabela 1) com os tempos médios de processamento para cada recurso e para cada forma e intensidade de distribuição de capacidades.

d) Flutuações estatísticas dos tempos de ciclo: o parâmetro geralmente utilizado para representar as flutuações estatísticas ou variabilidades em torno de um valor médio é o coeficiente de variação $(\mathrm{CV})$, o qual é definido como o valor médio de determinada variável dividido por seu desvio-padrão.

A distribuição triangular (para evitar valores negativos) foi escolhida como forma de representar dois níveis de flutuações $(\mathrm{CV}=0,2$ e $\mathrm{CV}=0,5)$ nos tempos de processamento dos recursos do modelo e, assim, se aproximar de uma distribuição normal truncada. Entretanto, a distribuição exponencial foi mantida para representar o terceiro nível de variabilidade $(\mathrm{CV}=1)$, justamente por estar presente em grande número de pesquisas relacionadas a desempenho de linhas de manufatura. e) Demanda: o modelo representa um mix de produção de um único item com demanda infinita, ou seja, tudo o que é produzido é vendido.

f) Estrutura do produto: a estrutura do produto é linear com cinco etapas de processamento, ou seja, não há operações de montagem.

g) Estoques: os estoques deverão ser distribuídos segundo os critérios presentes nos sistemas de gestão da produção a serem simulados. As taxas de produção da linha serão comparadas segundo cinco níveis máximos de estoque em processo $(5,7,9$, 13 e 17 peças em toda a linha) cujas características de alocação variam segundo o método de gestão empregado, que são:

- Kanban: a definição foi feita seguindo os corolários apresentados em Tayur (1993), em um estudo sobre a ótima alocação de estoques em linhas de produção controladas por Kanban. Para os cinco níveis máximos de estoques sugeridos, têm-se as seguintes configurações de distribuição de cartões:

5 cartões: 1-1-1-1-1

7 cartões: 1-2-1-2-1

9 cartões: 1-2-2-3-1

13 cartões: 1-4-3-4-1

17 cartões: $1-5-4-6-1$

Uma importante observação deve ser feita neste ponto. As configurações de distribuição de cartões Kanban mencionadas são ótimas, segundo Tayur (1993), apenas para linhas balanceadas. O autor menciona ainda que tais configurações não variam segundo as variabilidades (CV) dos tempos médios de processamento. No entanto, linhas não balanceadas podem possuir configurações distintas. Nesta pesquisa, entretanto, as configurações anteriores foram adotadas também para as linhas desbalanceadas.

- CONWIP: aqui a alocação de cartões é estabelecida para toda a linha, não sendo, portanto, estabelecidos níveis de estoque 
para cada recurso, mas para a linha como um todo.

- TPC: o controle de entrada de material à linha no TPC será determinado segundo a taxa de produção do recurso com restrição de capacidade (RRC). Será, portanto, estabelecido um nível máximo de estoque de material antes do recurso restritivo, ficando liberada a quantidade de material após o recurso restritivo. Serão estabelecidos diversos níveis de estoque antes do RRC. Para cada um desses níveis, mede-se o nível médio de WIP em toda a linha, permitindo que se faça, oportunamente, comparações com os demais sistemas de gestão da produção.

- ROP: o ROP exige que se determine o espaço ou a quantidade de estoque permitida entre cada recurso de produção. No entanto, a quantidade ótima de capacidade de estocagem não corresponde à mesma disposição encontrada para o Kanban. Isto por que as linhas controladas segundo o método ROP, ao contrário dos sistemas tipo Kanban, não ajustam dinamicamente as proteções nos recursos da linha, Muckstadt \& Tayur (1995a) e Muckstadt \& Tayur (1995b). Tal característica confere aos sistemas ROP uma alocação diferenciada de capacidades de estocagem quando se busca uma configuração ótima em termos de taxa de produção. El-Rayah (1979b) constatou, para linhas controladas segundo a abordagem ROP, que a mais eficiente forma de projetar uma linha em termos de maximização da taxa de produção é onde iguais quantidades de capacidades de proteção são alocadas a todos os recursos da linha. Assim, para cada nível máximo de estoque em processo permitido na linha, tem-se a seguinte configuração de capacidades de estocagem distribuídas entre cada par de recursos:

WIP igual a $5: 1-1-1-1$

WIP igual a 7: 1-2-2-1
WIP igual a 9: 2-2-2-2

WIP igual a $13: 3-3-3-3$

WIP igual a 17: 4-4-4-4

h) Matéria-prima: a disponibilidade de matéria-prima é ilimitada, o que garante que o primeiro recurso da linha tenha sempre material para processar.

i) Mecanismos de bloqueio: um recurso só não estará em operação se uma das duas condições estiver ocorrendo: 1 . o recurso não tem material para processar (isto nunca acontece com o primeiro recurso da linha devido à disponibilidade ilimitada de matéria-prima) e 2 . o recurso é bloqueado por indisponibilidade de espaço de estocagem e/ou ausência de autorização para produção (isso nunca ocorre com o último recurso da linha).

\section{Modelagem dos sistemas de PCP}

Cada um dos modelos representativos dos quatro sistemas de PCP adotados para a pesquisa possui algumas características peculiares detalhadas a seguir.

\subsection{0 sistema ROP}

Tem por característica fundamental o fato de que há limite máximo de estocagem entre recursos. Sempre que este limite é atingido o recurso que o precede é desautorizado a continuar produzindo, sendo desbloqueado toda vez que o estoque cai abaixo do valor máximo estabelecido.

\subsection{O sistema Kanban}

A lógica de funcionamento segue o modelo desenvolvido por Tayur (1993). Neste modelo, um cartão Kanban serve tanto para autorizar a produção de um recurso como para sinalizar ou permitir o transporte de peças para as células consecutivas. Nesta pesquisa, portanto, está sendo utilizado o modelo de sistema Kanban de um cartão ou sistema Kanban simples. 


\subsection{O sistema CONWIP}

O modelo CONWIP busca limitar o nível máximo de WIP em toda a linha de produção, permitindo que este flua livremente entre os recursos. É dado, portanto, tratamento igualitário entre os recursos da linha, não importando seu posicionamento nem seu nível de capacidade produtiva. A cada item finalizado pelo último recurso da linha é autorizada a liberação de matéria-prima para a manufatura de mais um item.

\subsection{0 sistema tambor-pulmão-corda}

Segundo a teoria sobre TPC, um sistema gerenciado segundo este método deve ser capaz de identificar o recurso com menor capacidade da fábrica e explorá-lo ao máximo. Como a demanda é infinita, o tambor deve indicar ao recurso restritivo (gargalo) que produza sempre e o mais rápido possível. Para garantir esse nível de produção, um pulmão deve ser criado antes desse recurso. Com o intuito de evitar que se libere material à linha acima do nível estabelecido para o pulmão, modelou-se o sistema de forma que, a cada peça produzida pelo gargalo, um novo item seja liberado à linha.

Um pré-requisito básico para aplicação do modelo TPC e estudo do efeito da exploração do recurso gargalo é que haja na linha um único e identificável recurso gargalo. A existência de mais de um recurso com restrição de capacidade é um complicador à implementação do método TPC, pois exige o uso de ferramentas computacionais que permitam que todas as restrições sejam devidamente exploradas. Essa limitação levou à exclusão das configurações balanceadas, bowl e alternada no estudo do modelo. A configuração linear decrescente, por outro lado, apesar de possuir apenas um gargalo, localiza-o no final da linha. Nesse caso, a aplicação do modelo TPC equivaleria ao CONWIP, sendo decidido que o estudo desse tipo de configuração ficaria alocado ao estudo do método CONWIP.

Em razão de algumas características particulares que envolvem os sistemas de gestão a serem comparados, a execução dos experimentos deverá possuir algumas particularidades de modo a permitir a correta análise dos resultados obtidos. Um ponto em comum aos sistemas ROP, Kanban e CONWIP é que em todos eles o nível de estoque máximo em processo não pode ultrapassar certo limite preestabelecido, que, por sua vez, é determinado pelo espaço total disponível na linha (ROP) ou pelo total de kanbans circulando por toda a linha (Kanban e CONWIP).

No TPC, há um valor-limite para o nível de estoque em processo entre o primeiro recurso da linha e o RRC, denominado de pulmão recurso, expresso na forma de tempo, que tem por objetivo evitar a parada do RRC por falta de alimentação dos recursos anteriores. $\mathrm{O}$ método TPC procura evitar que o gargalo pare por qualquer tipo de bloqueio imposto por um recurso localizado após ele na linha de fabricação. Tal procedimento exige que não haja limitação no nível de estoque em processo depois do RRC. Logo, ao analisar o que acontece em toda a extensão da linha, pode-se afirmar que não há um nível máximo de estoque em processo planejado no TPC.

Com a finalidade de superar esse problema, estabeleceu-se que os experimentos de simulação serão conduzidos observando-se, separadamente, os níveis médios e máximos de WIP nos modelos simulados. No entanto, a análise do método TPC ficará restrita ao estudo do nível médio de WIP no sistema.

Foram simulados ao todo 1.386 modelos distintos, como resultado das combinações de diversos parâmetros e variáveis utilizados. Cada modelo, por sua vez, foi simulado 50 vezes, e cada corrida teve a duração de 1.700 unidades de tempo, sendo ignorados os dados provenientes das primeiras 200 unidades de tempo (período de warm-up). A cada um dos 1.386 modelos registrou-se o throughput médio obtido, o nível médio de WIP na linha e, com exceção do TPC, o nível de WIP máximo.

$\mathrm{Na}$ análise que teve por base o nível máximo de WIP na linha, as comparações se deram a partir da relação direta entre os throughputs alcançados para o mesmo nível de WIP máximo. $\mathrm{Na}$ análise a partir do nível médio de WIP, por não ser possível uma comparação 
direta, já que os níveis médios de WIP são distintos para cada modelo, elaboraram-se gráficos com tendências de desempenho para cada modelo, em que no eixo das abscissas plotou-se o nível médio de WIP e nas ordenadas, o throughput médio medido neste ponto. Todo o estudo foi realizado, então, comparando-se essas tendências. Por fim, para facilitar a interpretação e a análise dos resultados, cada gráfico teve seu eixo das abscissas estratificado em três partes, as quais foram denominadas de níveis baixo, médio e alto de WIP médio.
Com o intuito de demonstrar como as observações foram geradas, um exemplo específico será apresentado. Frisa, entretanto, que todas as análises foram efetuadas seguindo a mesma metodologia empregada neste caso em particular.

\section{Exemplo de análise segundo o nível médio de WIP}

Exemplo: Análise dos sistemas de PCP empregados em uma linha segmentada com $\mathrm{CV}=$ 1 e GD ${ }_{(\mathrm{bxo})}$.

Tabela 2 - Dados de desempenho do sistema TPC em uma linha segmentada com

$$
\mathrm{CV}=1 \text { e GD } \text { (bxo) }^{\text {. }}
$$

\begin{tabular}{l|c|c|c|c|c|c}
\hline \multicolumn{7}{c}{ Sistema tambor-pulmão-corda } \\
\hline Modelo & T2SEG13 & T3SEG13 & T4SEG13 & T5SEG13 & T6SEG13 & T7SEG13 \\
\hline OP & 25,067 & 30,129 & 33,471 & 35,941 & 37,751 & 39,074 \\
WIP médio & 3,466 & 5,103 & 6,746 & 8,427 & 10,008 & 11,540 \\
Modelo & T8SEG13 & T9SEG13 & T10SEG13 & T11SEG13 & T12SEG13 & \\
OP & 40,145 & 41,017 & 41,725 & 42,364 & 42,899 & \\
WIP médio & 13,087 & 14,583 & 16,012 & 17,439 & 18,900 & \\
\hline
\end{tabular}

Tabela 3 - Dados de desempenho do sistema CONWIP em uma linha segmentada com $\mathrm{CV}=1$ e $\mathrm{GD}_{(\mathrm{bxo})^{\circ}}$

\begin{tabular}{l|c|c|c|c|c}
\hline \multicolumn{6}{c}{ Sistema CONWIP } \\
\hline \multicolumn{1}{c|}{ Modelo } & C5SEG13 & C7SEG13 & C9SEG13 & C13SEG13 & C17SEG13 \\
\hline OP & 28,047 & 32,220 & 34,989 & 38,363 & 40,442 \\
WIP médio & 4,552 & 6,237 & 7,892 & 11,138 & 14,323 \\
\hline
\end{tabular}

Tabela 4 - Dados de desempenho do sistema Kanban em uma linha segmentada $\operatorname{com} \mathrm{CV}=1$ e $\mathrm{GD}_{(\mathrm{bxo})^{\circ}}$.

\begin{tabular}{l|c|c|c|c|c}
\hline \multicolumn{6}{c}{ Sistema Kanban } \\
\hline \multicolumn{1}{c|}{ Modelo } & K5SEG13 & K7SEG13 & K9SEG13 & K13SEG13 & K17SEG13 \\
\hline OP & 24,594 & 29,541 & 32,825 & 37,072 & 39,417 \\
WIP médio & 3,791 & 5,309 & 6,476 & 9,934 & 12,472 \\
\hline
\end{tabular}


Tabela 5 - Dados de desempenho do sistema ROP em uma linha segmentada $\operatorname{com} \mathrm{CV}=1$ e GD ${ }_{(\mathrm{bxo})}$.

\begin{tabular}{l|c|c|c|c|c}
\hline \multicolumn{6}{c}{ Sistema Reorder Point } \\
\hline \multicolumn{1}{c|}{ Modelo } & J5SEG13 & J7SEG13 & J9SEG13 & J13SEG13 & J17SEG13 \\
\hline OP & 24,594 & 28,016 & 30,737 & 34,301 & 36,697 \\
WIP médio & 3,791 & 5,012 & 6,139 & 8,331 & 10,441 \\
\hline
\end{tabular}

Primeiramente, foram elaboradas tabelas (Tabelas 2 a 5) com as informações necessárias à elaboração dos gráficos. A partir das tabelas, gerou-se o gráfico da Figura 1.

Para viabilizar a análise dos dados, o eixo das abscissas (eixo que mede o nível de WIP médio) foi dividido em três regiões aproximadamente iguais, as quais representam três níveis de WIP médio (níveis baixo, médio e alto).

Como critério geral sempre se procura manter cada uma das três regiões com a mesma faixa de WIP médio. Dessa maneira, os gráficos das Figuras 2, 3 e 4 foram gerados a partir do gráfico da Figura 1. Observando os gráficos, buscou-se analisar, para cada nível de WIP (baixo, médio e alto), o desempenho relativo de cada objeto de estudo, neste caso, os sistemas de PCP.

\section{Resultados}

São apresentados a seguir alguns resultados obtidos ao longo da pesquisa, os quais, primeiramente, serão discutidos segundo os critérios de alocação de capacidades e, posteriormente, segundo os sistemas de PCP estudados.

\subsection{Os critérios de alocação de capacidades}

Quando analisadas à luz do sistema ROP, as configurações na forma bowl e balanceada obtiveram bons resultados, o que confirma parte das pesquisas na área.

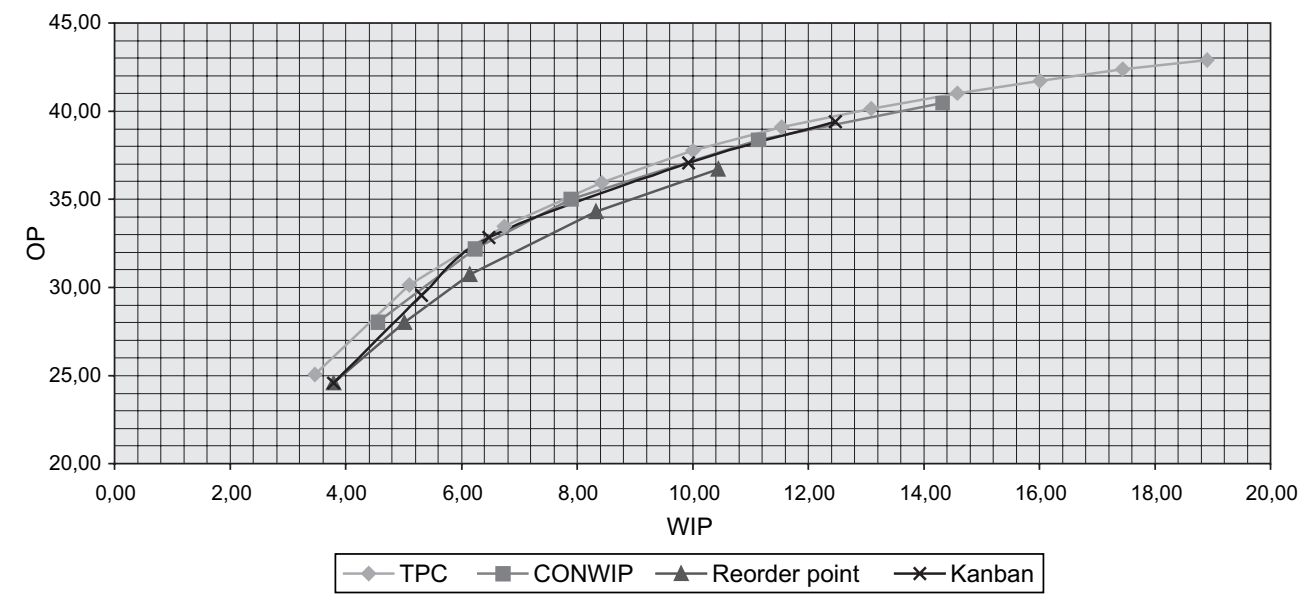

Figura 1 - Gráfico de desempenho dos sistemas de PCP em uma linha segmentada $\operatorname{com} \mathrm{CV}=1$ e GD (bxo) $^{\text {. }}$ 


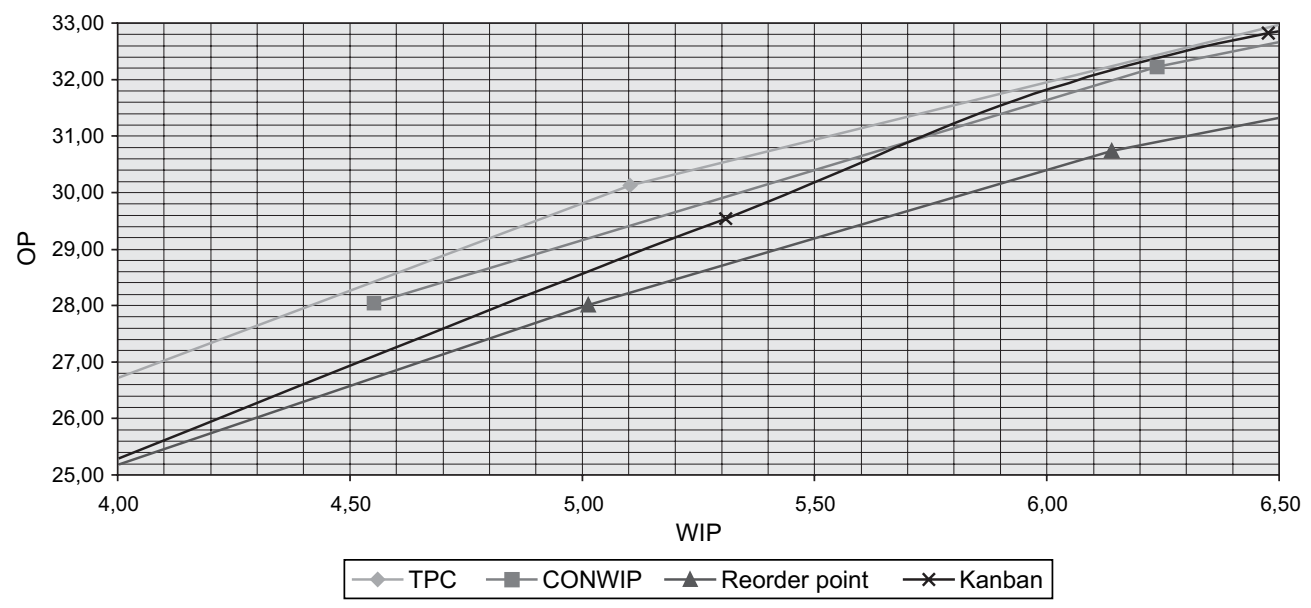

Figura 2 - Gráfico de desempenho dos sistemas de PCP em uma linha segmentada com $\mathrm{CV}=1, \mathrm{GD}_{(\mathrm{bxo})}$ e WIP médio medido em seu nível baixo.

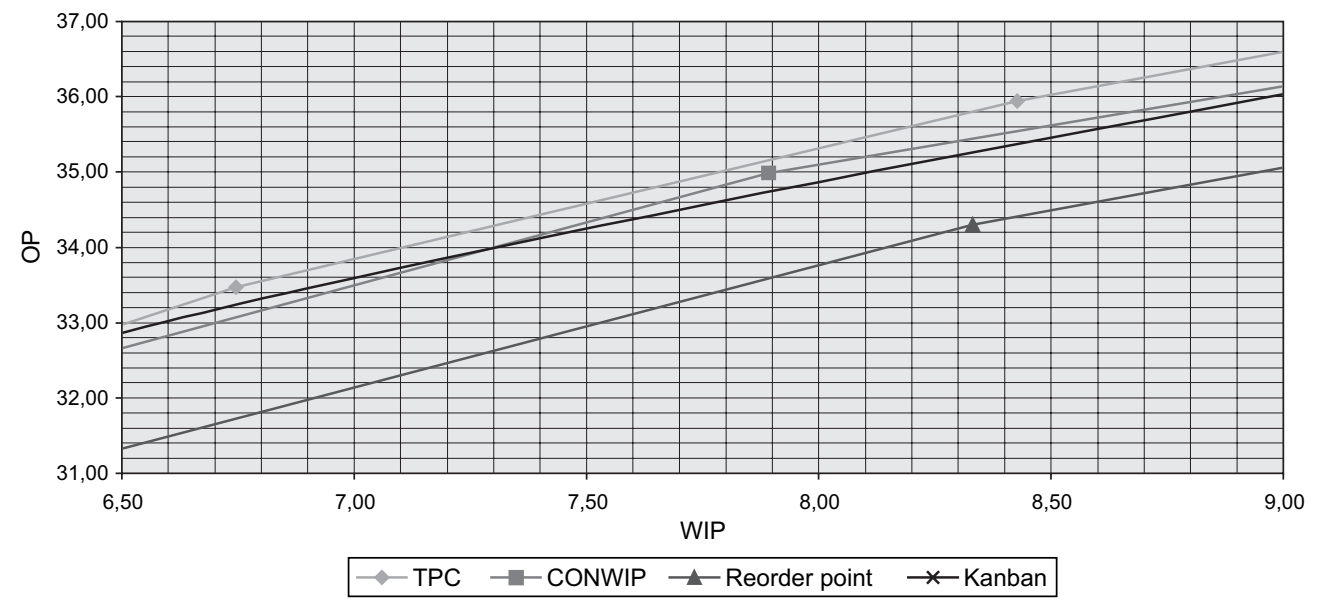

Figura 3 - Gráfico de desempenho dos sistemas de PCP em uma linha segmentada com $\mathrm{CV}=1, \mathrm{GD}_{(\mathrm{bxo})}$ e WIP médio medido em seu nível médio.

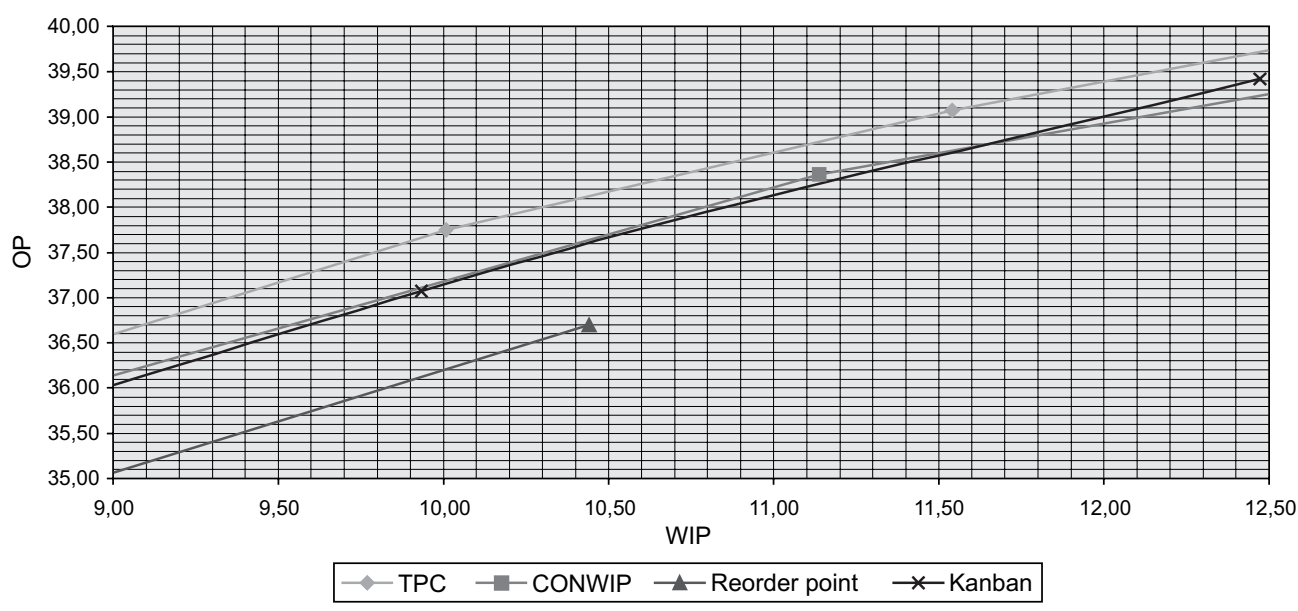

Figura 4 - Gráfico de desempenho dos sistemas de PCP em uma linha segmentada com $\mathrm{CV}=1, \mathrm{GD}_{(\mathrm{bxo})}$ e WIP médio medido em seu nível alto. 
Também é fato que, como concluído em outros estudos, o fenômeno bowl fica mais evidente e seus resultados superam a alocação balanceada quando o nível de WIP é mais baixo e o CV é relativamente alto. Para pequenos níveis de CV e altos níveis de WIP a alocação balanceada se torna preferível.

Porém, a análise dos resultados possibilitou que se verificassem outros tipos de alocação de capacidades que também apresentaram bons desempenhos e que em algumas situações até mesmo superaram as alocações balanceada e bowl. Observou-se, por exemplo, segundo o foco no nível máximo de WIP, que, quando o nível de WIP pesquisado foi de cinco unidades, as alocações step (CV iguais a 0,2, 0,5 e 1,0) e mix (CV igual a 0,2) superaram a balanceada. Também observou-se que, quando o nível de WIP foi de 7 unidades, as alocações segmentadas e em V (CV iguais a 0,2, $0,5$ e 1,0$)$ e a step (CV igual a 1,0) superaram não apenas a alocação balanceada, mas também a alocação bowl. Embora esses resultados sejam advindos do fato de que a distribuição de capacidades de estocagem, quando o nível de WIP no sistema é de sete unidades, privilegia os recursos centrais e de que nas alocações segmentada, em V e step o recurso gargalo é mais no centro da linha; os resultados continuam sendo significativos.

Ao observar os resultados provenientes da análise em torno do nível médio de WIP, percebe-se que outras alocações se destacam, como a linear crescente, a step e, quando o nível de variabilidade é 0,2 , também a alocação em V.

Não há, portanto, considerando a análise das potencialidades dos diversos critérios de alocações de capacidade à luz do sistema ROP, nada que permita afirmar a predominância das alocações balanceadas e bowl sobre todas as demais. Quando o estudo extrapola para outros sistemas de PCP, os resultados novamente voltam a confirmar a não predominância absoluta das alocações balanceadas e bowl sobre as demais. No sistema Kanban, quando a análise se dá em torno do nível máximo de WIP, as alocações step, mix, V e LD superam, em muitas situações, a alocação balanceada ou a bowl. Observando os resultados, segundo o nível médio de WIP, novamente nota-se que certas situações são mais favoráveis a outros critérios do que à alocação balanceada ou a bowl, como a step e a linear crescente, mais uma vez.

Analisando agora os critérios de alocação sob o CONWIP e observando os resultados focando-se o nível máximo de WIP, percebe-se mais uma vez que outras alocações podem se destacar, como a V, que supera a balanceada quando o nível de WIP é 5 e o CV é 0,2. No entanto, é no sistema CONWIP que de fato a alocação balanceada se destaca, sendo a melhor opção em todas as demais situações.

Porém, não se pode afirmar o mesmo quanto ao método bowl. Quando o CV é 0,2 ele perde apenas para alocação $\mathrm{V}$ (dentre as desbalanceadas); com o aumento do $\mathrm{CV}$, ele se torna inferior a diversas outras alocações.

Se a alocação balanceada parece ser a melhor opção no sistema CONWIP, este argumento se desfaz quando a análise se dá segundo o nível médio de WIP. Nesse caso, as alocações step e linear crescente parecem superar a balanceada quando a variabilidade nos tempos de processamento é relativamente alta.

Embora não tenha sido possível aplicar o método TPC às linhas balanceadas e em bowl (por possuírem mais de um gargalo) e, portanto, validar as conclusões acima em mais um tipo de PCP, considera-se que os resultados obtidos nesta pesquisa permitem reafirmar que nada indica haver melhor critério de alocação para todas as situações. Tão pouco os melhores critérios em situações particulares se resumem sempre à alocação balanceada ou bowl .

\subsection{As políticas de PCP}

Embora a simplicidade dos modelos adotados para pesquisa dificulte a avaliação das reais potencialidades de cada sistema, os resultados aqui alcançados permitem que se faça, no mínimo, algumas correções em certos dogmas geralmente aceitos ou defendidos por alguns.

Diversos trabalhos sugerem, por exemplo, que os sistemas CONWIP são superiores aos sistemas Kanban (Spearman et al., 1990; Hopp $\&$ Spearman, 1996). Isto se deveria ao fato de que o sistema CONWIP permite maior flexibi- 
lidade na maneira como os estoques fluem entre recursos, possibilitando que gargalos, temporários ou não, sejam convenientemente protegidos.

De fato, quando a análise se dá em torno do nível máximo de WIP, o sistema CONWIP é sempre superior ao Kanban. Por outro lado, quando a análise é focada sobre o nível médio de WIP, o sistema Kanban passa a ter, em algumas situações, desempenhos superiores ao CONWIP.

Tayur (1993) e Muckstadt \& Tayur (1995a, b) sugeriram em suas pesquisas que o sistema Kanban supera o CONWIP em termos de throughput por nível médio de WIP. Porém, as pesquisas aqui desenvolvidas indicaram que essa superioridade é contingencial, podendo o CONWIP superar o Kanban dependendo do tipo de alocação de capacidade, do nível de WIP, do grau de desbalanceamento e do nível de variabilidade dos processos produtivos.

Spearman et al. (1990) observaram que, ao permitir que WIP se concentre em frente ao recurso gargalo, o CONWIP pode funcionar com níveis mais baixos de WIP que o Kanban. Os autores não fazem distinção se a referência é em torno do nível médio ou máximo de WIP. Se o interesse estiver no nível de WIP máximo, o CONWIP supera o Kanban em quaisquer níveis de WIP, não necessariamente no baixo. Se o interesse é pelo nível de WIP médio, nada na pesquisa parece indicar um padrão de comportamento que permita afirmar que o CONWIP é melhor que o Kanban quando o nível de WIP é baixo. O desempenho do sistema CONWIP em relação ao Kanban parece depender de outros fatores além do WIP, como níveis de variabilidades dos processos produtivos e da maneira como as capacidades produtivas estão alocadas entre os recursos.

Pela maneira como o recurso gargalo é explorado, era de se esperar que o sistema tambor-pulmão-corda (TPC) fosse de fato superior aos demais sistemas de PCP. Os resultados, no entanto, refletem apenas parcialmente essa asserção. Lembrando que o sistema TPC só pode ser analisado segundo níveis médios de WIP, foi evidenciado que, dada uma condição de linha de manufatura, ou seja, empregando-se determinado tipo de alocação de capacidade (desde que contenha um único gargalo), com determinados graus de desbalanceamento, níveis de WIP e CV, o TPC jamais foi superado.

Isso não significa, contudo, que o TPC tenha sido a melhor opção para todas as situações. Foi constatado que seu desempenho superou todas as demais combinações PCP/alocação apenas quando o $\mathrm{CV}$ foi alto (1) e o grau de desbalanceamento, baixo. Esse resultado permite outras considerações.

Primeiramente, talvez ao contrário do que se possa supor, o sistema TPC foi relativamente superior aos demais sistemas de PCP quando o grau de desbalanceamento foi baixo, não alto. Uma vez que o sistema TPC foi concebido com o objetivo de permitir que o recursos gargalo seja explorado ao máximo, se poderia esperar que, quanto mais desbalanceada a linha, e, portanto, com um gargalo cada vez mais evidenciado, melhor explorado seria o recurso gargalo em relação aos demais sistemas de PCP. Entretanto, não foi isso o que se verificou. Os melhores desempenhos relativos do TPC ocorreram quando o grau de desbalanceamento foi menor.

Outro ponto interessante diz respeito ao desempenho alcançado pelo TPC em termos de nível de WIP. Como a teoria sobre TPC afirma ser importante localizar as proteções na forma de WIP apenas nos pontos onde necessário, isto é, protegendo operações críticas do processo de manufatura, poderia-se esperar que, quanto mais baixo o nível de WIP na linha, mais racionalmente o TPC faria uso do WIP. No entanto, isso não prevaleceu. Em diversas situações, o desempenho relativo do sistema TPC foi melhor em níveis mais altos de WIP.

Há de se considerar, entretanto, que o sistema TPC foi concebido, ou pelo menos é bastante apto, para operar em linhas mais complexas, até mesmo em fábricas tipo job-shop. Pode-se esperar, então, que, em razão da alta simplicidade dos modelos aqui adotados, o total potencial do sistema TPC não tenha sido aproveitado. Por outro lado, um prérequisito para o bom funcionamento dos sistemas CONWIP e principalmente do sistema Kanban é que a fábrica tenha fluxo produtivo suave, com 
pequenas flutuações, tanto internas (baixo $\mathrm{CV}$ e mix reduzido) quanto externas (mix pouco flutuante). Essas características podem levar a certa parcialidade dos resultados em favor dos sistemas CONWIP e Kanban.

\section{Conclusões}

A análise dos resultados evidencia a estreita relação entre políticas de PCP e técnicas de alocação de capacidades.

Algumas conclusões podem ser então descritas, as quais serão apresentadas à luz das hipóteses apresentadas no início deste trabalho e reeditadas a seguir:

Conclusão 1: O desempenho de um método de alocação de capacidades depende fortemente do sistema de gestão da produção empregado e este desempenho também depende dos níveis de estoque em processo (WIP), variabilidades nos tempos de processamento $(\mathrm{CV})$ ou graus de desbalanceamento (GD) entre recursos.

Conclusão 2: O desempenho de um sistema de PCP depende fortemente do método de alocação de capacidades adotado e este desempenho depende do nível de WIP planejado, da variabilidade dos tempos de processamento dos recursos e, no caso de linhas desbalanceadas, do grau de desbalanceamento dos recursos.

Conclusão 3: Não há combinação ótima "configuração de distribuição de capacidades" $x$ "sistemas de gestão da produção" que maximize a taxa de produção em quaisquer circunstâncias.
Os resultados mostraram que a eficiência das diversas combinações depende de a análise estar focada no nível de WIP máximo ou médio. No primeiro caso, em que se exclui o sistema TPC, ficou evidente que a melhor combinação foi com o sistema CONWIP empregado numa linha balanceada. A única exceção se deu quando o CV foi de 0,2 e o nível de WIP máximo foi 5. Nesse caso, a melhor combinação foi com o sistema CONWIP aplicado a uma alocação em V com grau de desbalanceamento baixo (veja a Tabela 6).

Quando o enfoque está no nível médio de WIP, a cada situação, variando-se o CV, o grau de desbalanceamento e o nível médio de WIP, encontram-se diferentes combinações PCP $x$ alocação de capacidade que possibilitam os melhores resultados (veja a Tabela 8).

Conclusão 4: Não há um sistema de PCP que se sobressaia em relação aos demais sob quaisquer critérios de alocação de capacidades. Mais uma vez a resposta vai depender de o enfoque estar no nível máximo ou médio de WIP. Se o foco estiver sobre o nível de WIP máximo (exclui-se, portanto, o TPC), sob quaisquer critérios de alocação de capacidade e ainda sob as mesmas condições (GD, CV e WIP), o sistema CONWIP sempre será superior ao Kanban e ao ROP. O Kanban, por sua vez, jamais será superado pelo ROP.

Entretanto, focando o nível médio de WIP e observando os resultados, pode-se verificar que, mudando o tipo de critério de alocação de capacidades, altera-se o predomínio de um sistema de PCP em relação aos demais (veja a Tabela 7).

\section{Tabela 6 - As melhores combinações PCP/alocação de capacidades sob o enfoque do nível máximo de WIP.}

\begin{tabular}{|c|c|c|c|c|c|c|c|c|c|c|}
\hline \multirow{2}{*}{$\mathrm{CV}$} & \multicolumn{2}{|c|}{$\mathrm{WIP}=5$} & \multicolumn{2}{|c|}{$\mathrm{WIP}=7$} & \multicolumn{2}{|c|}{$\mathrm{WIP}=9$} & \multicolumn{2}{|c|}{$\mathrm{WIP}=13$} & \multicolumn{2}{|c|}{$\mathrm{WIP}=17$} \\
\hline & Sistema & $\mathbf{O P}$ & Sistema & $\mathbf{O P}$ & Sistema & OP & Sistema & OP & Sistema & OP \\
\hline 0,2 & CWP/V & 43,445 & CWP/bal & 47,357 & CWP/bal & 48,377 & CWP/bal & 49,209 & CWP/bal & 49,461 \\
\hline 0,5 & CWP/bal & 35,982 & CWP/bal & 40,842 & CWP/bal & 43,203 & CWP/bal & 45,538 & CWP/bal & 46,736 \\
\hline 1,0 & CWP/bal & 28,057 & CWP/bal & 32,241 & CWP/bal & 35,016 & CWP/bal & 38,406 & CWP/bal & 40,512 \\
\hline
\end{tabular}




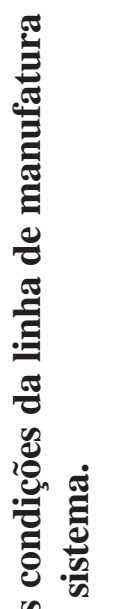

$$
\begin{aligned}
& \text { |言| }
\end{aligned}
$$

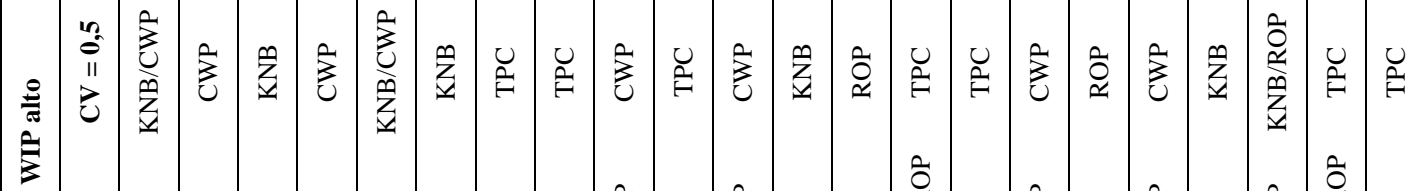

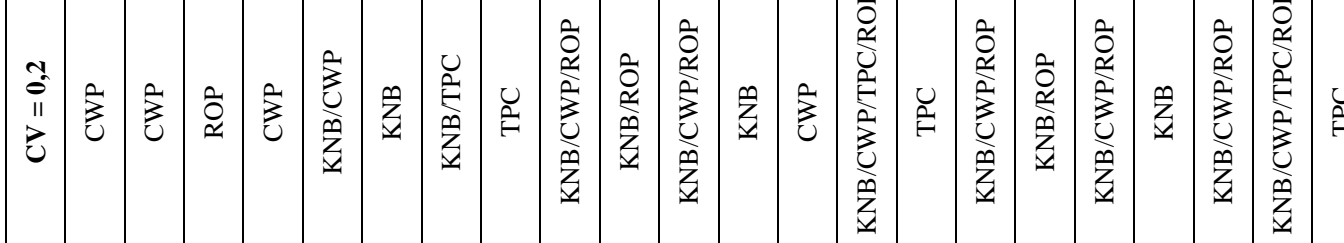

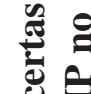

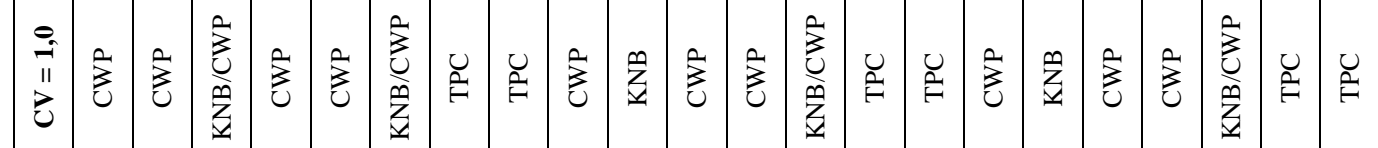

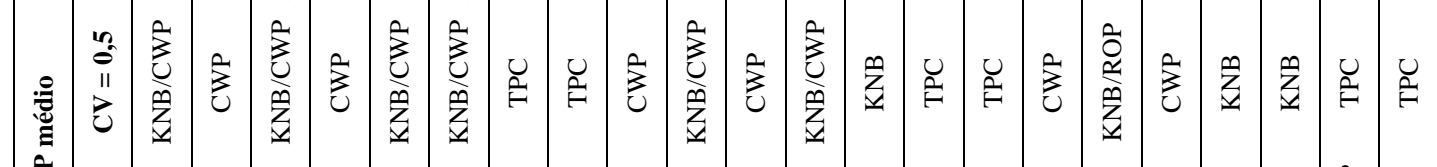

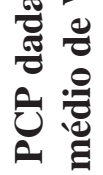

$\approx$

焉

:

妾

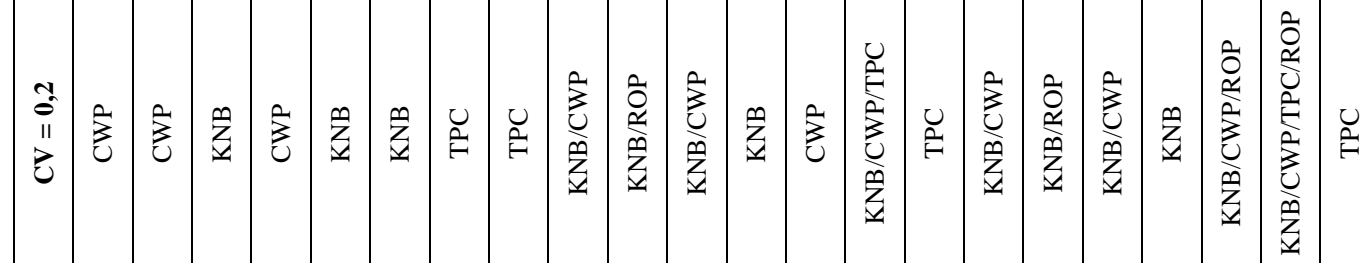

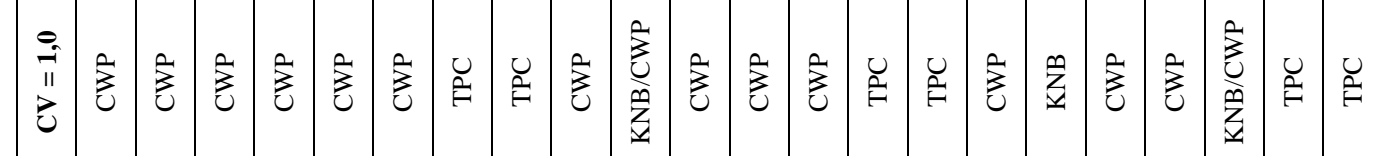

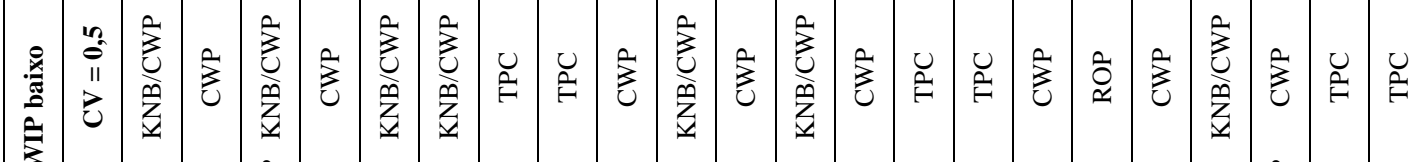

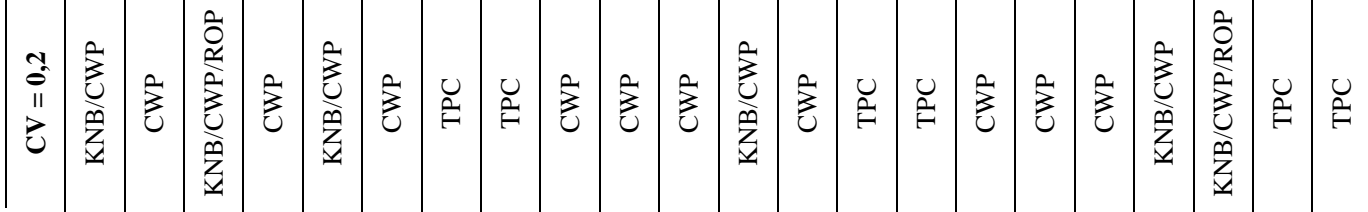

要

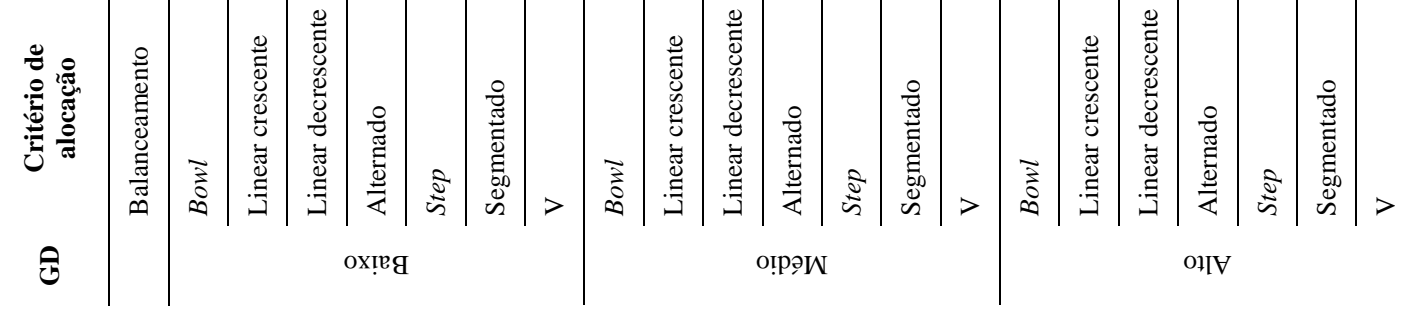


Tabela 8 - Quadro resumo com as melhores combinações PCP/alocação de capacidades segundo o nível médio de WIP no sistema.

\begin{tabular}{|c|c|c|c|c|}
\hline \multirow{2}{*}{ WIP } & \multirow{2}{*}{$\begin{array}{c}\text { Coeficiente de } \\
\text { variabilidade }\end{array}$} & \multicolumn{3}{|c|}{ Grau de desbalanceamento } \\
\hline & & Baixo & Médio & Alto \\
\hline \multirow{3}{*}{ 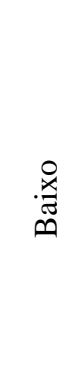 } & $\mathrm{CV}=0,2$ & $\begin{array}{l}\mathrm{KNB} / \text { step e } \\
\mathrm{CWP} / \text { step }\end{array}$ & CWP/bal & $\begin{array}{c}\mathrm{KNB} / \mathrm{bal} \mathrm{e} \\
\mathrm{CWP} / \mathrm{bal}\end{array}$ \\
\hline & $\mathrm{CV}=0,5$ & $\begin{array}{l}\mathrm{KNB} / \text { step, KNB/LC, } \\
\text { CWP/step e TPC/seg }\end{array}$ & $\begin{array}{l}\mathrm{KNB} / \mathrm{step} \text { e } \\
\mathrm{CWP} / \mathrm{step}\end{array}$ & $\begin{array}{c}\mathrm{KNB} / \mathrm{LC} \text { e } \\
\mathrm{CWP} / \mathrm{bal}\end{array}$ \\
\hline & $\mathrm{CV}=1,0$ & TPC/seg & $\begin{array}{l}\mathrm{KNB} / \mathrm{step} \text { e } \\
\mathrm{CWP} / \mathrm{step}\end{array}$ & $\mathrm{KNB} /$ step \\
\hline \multirow{3}{*}{ 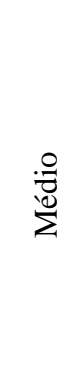 } & $\mathrm{CV}=0,2$ & CWP/bal & CWP/bal & $\begin{array}{c}\mathrm{KNB} / \mathrm{bal} \mathrm{e} \\
\mathrm{CWP} / \mathrm{bal}\end{array}$ \\
\hline & $\mathrm{CV}=0,5$ & $\begin{array}{l}\mathrm{KNB} / \mathrm{LC} \mathrm{e} \\
\mathrm{KNB} / \mathrm{step}\end{array}$ & CWP/bal & $\begin{array}{c}\mathrm{KNB} / \mathrm{bal} \mathrm{e} \\
\mathrm{CWP} / \mathrm{bal}\end{array}$ \\
\hline & $\mathrm{CV}=1,0$ & TPC/seg & $\mathrm{KNB} / \mathrm{step}$ & $\begin{array}{l}\mathrm{KNB} / \mathrm{step} \\
\mathrm{CWP} / \mathrm{step}\end{array}$ \\
\hline \multirow{3}{*}{$\stackrel{\circ}{\gtrless}$} & $\mathrm{CV}=0,2$ & $\mathrm{CWP} / \mathrm{bal}$ & CWP/bal & CWP/bal \\
\hline & $\mathrm{CV}=0,5$ & $\mathrm{KNB} /$ step & $\begin{array}{c}\mathrm{KNB} / \mathrm{bal} \mathrm{e} \\
\mathrm{CWP} / \mathrm{bal}\end{array}$ & $\begin{array}{c}\mathrm{KNB} / \mathrm{bal} \mathrm{e} \\
\mathrm{CWP} / \mathrm{bal}\end{array}$ \\
\hline & $\mathrm{CV}=1,0$ & TPC/seg & CWP/step & $\mathrm{CWP} / \mathrm{bal}$ \\
\hline
\end{tabular}

Portanto, não há um sistema de PCP que responda bem a todas as situações.

Conclusão 5: Não há um critério de alocação de capacidades que se sobressaia em relação aos demais sob quaisquer sistemas de PCP. Novamente, a resposta dependerá de o enfoque estar no nível máximo ou médio de WIP.

Sob o enfoque do nível máximo de WIP, a Tabela 9 demonstra que as melhores alocações de capacidades podem mudar ao se alterar o tipo de sistema de PCP. Sob o enfoque do nível médio de WIP, a Tabela 10 demonstra, mais uma vez, não haver predomínio de nenhum critério de alocação de capacidades sob os demais, em quaisquer circunstâncias de PCP. Portanto, não há um critério de alocação de capacidade que responda bem a todas as situações. Como consideração final, pode-se dizer que a maior contribuição deste trabalho são os fortes indícios no sentido de afirmar que os desempenhos, tantos dos diversos critérios de alocação de capacidades quanto dos sistemas de PCP, estão não apenas intimamente interligados, mas também dependem do nível de WIP na linha, da maneira de medir o WIP (máximo ou médio), do coeficiente de variabilidade dos tempos de processamento dos recursos e até mesmo do grau de desbalanceamento das linhas. 


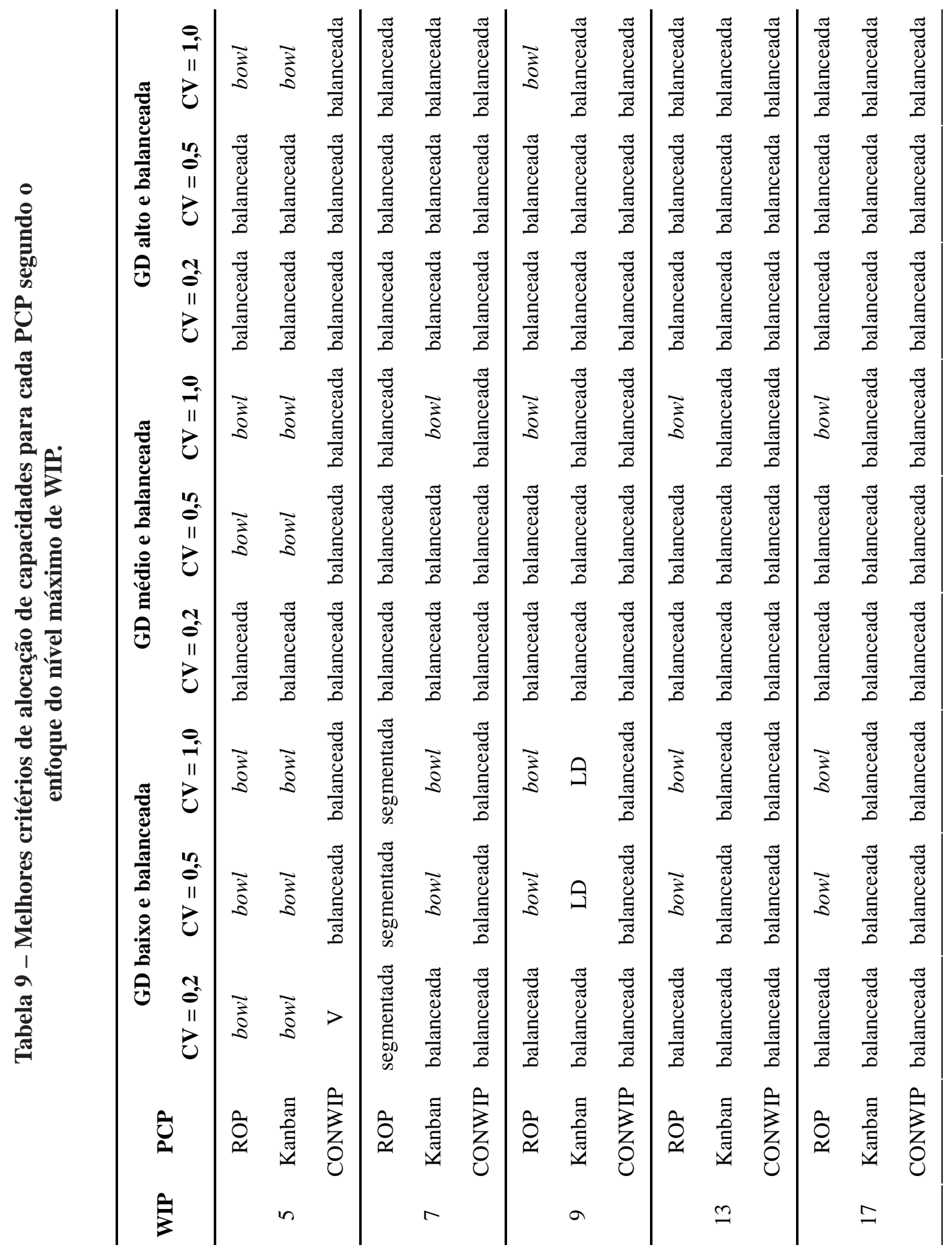




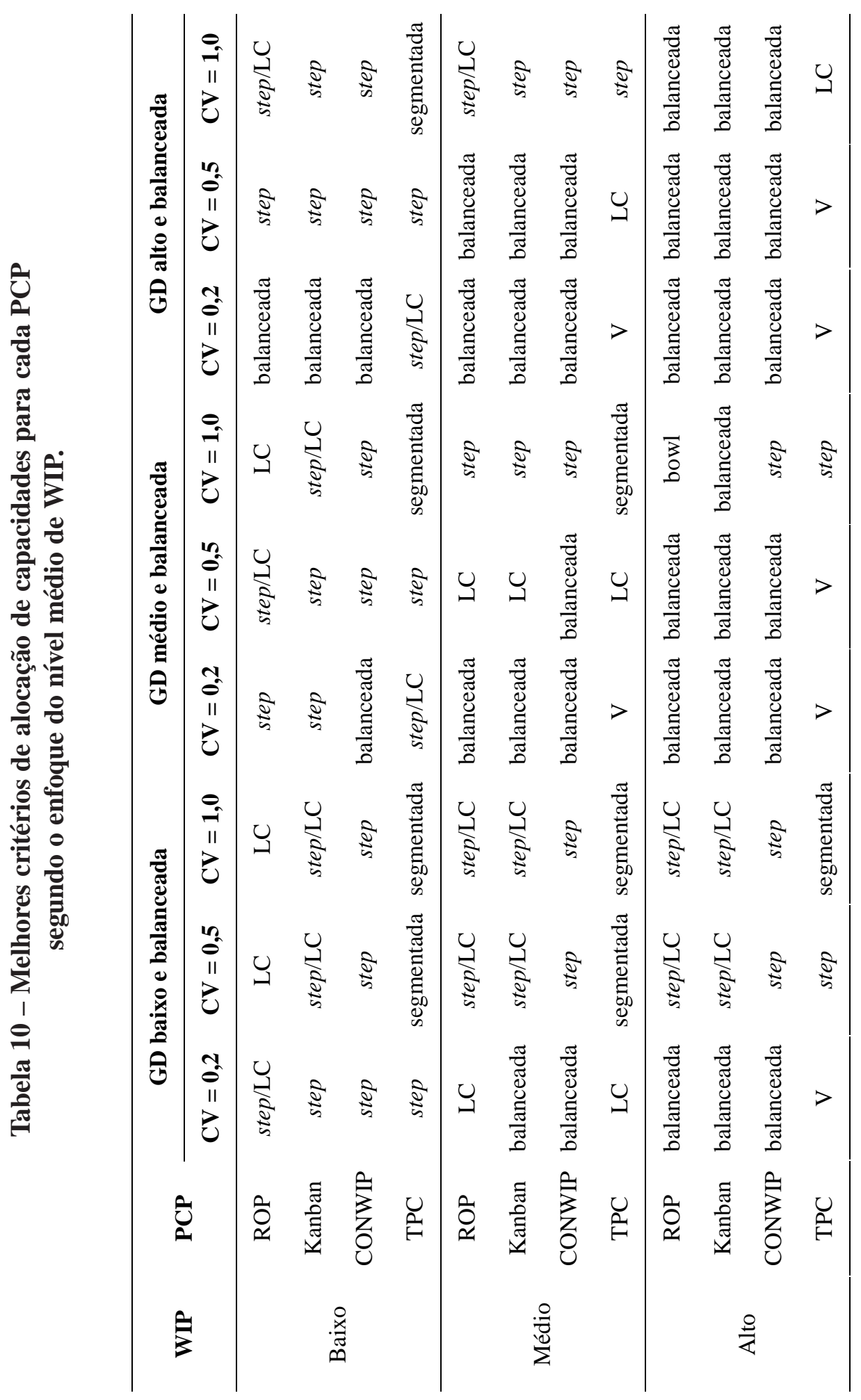


Assim, determinado sistema de PCP pode ser muito bom para situações particulares e não tão bom para outras. Certo critério de alocação de capacidades pode ser muito eficiente quando aplicado a determinado sistema de PCP e pouco eficiente em outros. O que se espera, portanto, com os resultados aqui alcançados, é que os temas "projetos de linhas" e "sistemas de PCP" deixem de ser tratados de maneira isolada e independente e passem a fazer parte de um conjunto único de estudo, não apenas para fins acadêmicos, mas também nas aplicações reais de chão-de-fábrica.

\section{Agradecimento}

Agradecemos à Fapesp pelo aporte de recursos sem os quais esta pesquisa se tornaria inviável.

\section{Referências Bibliográficas}

AGGARWAL, S. C. MRP, JIT, OPT, FMS? Making sense of production operations systems. Harward Business Review, v. 63, n. 5, p. 8-16, sep./oct. 1985. ATWATER, J. B.; CHAKRAVORTY, S. S. Does protective capacity assist managers in competing along time-based dimensions? Production and Inventory Management Journal, third quarter, p. 53-59, 1994.

BARTEN, K. A queueing simulator for determining optimum inventory levels in a sequential process. Journal of Industrial Engineering, v. 13, n. 4, p. 245 252, 1962.

BERKLEY, B. J. Tandem queues and kanbancontrolled lines. International Journal of Production Research, v. 29, n. 10, p. 2057-2081, 1991.

BURBIDGE, J. L. Production planning and control a personal philosophy. Production Planning \& Control, v. 1, n. 1, p. 3-16, 1990.

CHAKRAVORTY, S. S.; ATWATER, J. B. A comparative study of line design approaches for serial productions systems. International Journal of Operations and Production Management, v. 16, n. 6, p. 91-108, 1996.

CONWAY, R.; MAXWELL, W.; MCCLAIN, J. O.; THOMAS, L. J. The role of work-in-process inventory in serial production lines. Operations Research, v. 36, n. 2, p. 229-241, 1988.

COOK, D. P. A simulation comparison of traditional, JIT, and TOC manufacturing systems in a flow shop with bottlenecks. Production and Inventory Management Journal, first quarter, p. 73-78, 1994.

DAVIS, L. E. Pacing effects on manned assembly lines. International Journal of Production Research, v. 4, n. 3, p. 171-184, 1966.

EL-RAYAH, T. E. The efficiency of balanced and unbalanced production lines. International Journal of Production Research, v. 17, n. 1, p. 61-75, 1979a.
EL-RAYAH, T. E. The effect of inequality of interstage buffer capacities and operations time variability on the efficiency of production line systems. International Journal of Production Research, v. 17, n. 1, p. 77-89, 1979b.

FRY, T. D.; RUSSELL, G. R. Capacity allocation strategies in a hypothetical job-shop. International Journal of Production Research, v. 31, n. 5, p. 10971115, 1993.

GOLDRATT, E. M. The unbalanced plant. APICS 24th Annual International Conference Proceedings, 1981.

GOLDRATT, E. M.; COX, J. A meta: um processo de aprimoramento contínuo. São Paulo: Educator, 1995. GOLDRATT, E. M.; FOX, R. E. A corrida. São Paulo: IMAM, 1989.

GSTETTNER, S.; KUHN, H. Analysis of production control systems kanban and CONWIP. International Journal of Production Research, v. 34, n. 11, p. 3253-3273, 1996.

HILLIER, F. S.; BOLING, R. W. The effect of some design factors on the efficiency of production lines with variable operations times. The Journal of Industrial Engineering, v. 17, n. 12, p. 651-658, 1966.

HILLIER, F. S.; BOLING, R. W. On the optimal allocation of work in symmetrically unbalanced production line systems with variable operation times. Management Science, v. 25, n. 8, p. 721-728, 1979.

HILLIER, F. S.; SO, K. C. On the robustness of the bowl phenomenon. European Journal of Operational Research, v. 89, p. 496-515, 1996.

HOPP, W. J.; SPEARMAN, M. L. Factory physics: foundations of manufacturing management. Boston, Massachusetts: Irwin/McGraw-Hill, 1996.

HUANG, C. C.; KUSIAK, A. Manufacturing control with a push-pull approach. International Journal of Production Research, v. 36, n. 1, p. 251-275, 1998. 
MILTENBURG, J. Comparing JIT, MRP, and TOC, and embedding TOC into MRP. International Journal of Production Research, v. 35, n. 4, p.1147-1169, 1997. MONDEN, Y. Sistema Toyota de Produção. São Paulo: IMAM, 1984.

MUCKSTADT, J. A.; TAYUR, S. R. A comparison of alternative Kanban control mechanisms. I. Background and structural results. IIE Transactions, v. 27, p. 140-150, 1995 a.

MUCKSTADT, J. A.; TAYUR, S. R. A comparison of alternative Kanban control mechanisms. II. Experimental results. IIE Transactions, v. 27, p.151-161, 1995b.

NEWMAN, W. R.; SRIDHARAN, V. Manufacturing planning and control: is there one definitive answer? Production and Inventory Management Journal, first quarter, p. 50-53, 1992.

PATTERSON, R. L. Markov processes occurring in the theory of traffic flow through an $\mathrm{N}$-stage stochastic service system. Journal of Industrial Engineering, v. 15, n. 4, p.188-193, 1964.

PAYNE, S.; SLACK, N.; WILD, R.: A note on the operating characteristics of balanced and unbalanced production flow lines. International Journal of Production Research, v. 10, n. 1, p. 93-98, 1972.

PIKE, R.; MARTIN, G. E. The bowl phenomenon in unpaced lines. International Journal of Production Research, v. 32, n. 3, p. 483-499, 1994.

PTAK, C. A. MRP, MRPII, OPT, JIT, and CIM: succession, evolution, or necessary combination. Production and Inventory Management Journal, v. 32, n. 2, p. 7-11, 1991.
RAMSAY, M. L.; BROWN, S.; TABIBZADEH, K. Push, pull, and squeeze shop floor control with computer simulation. Industrial Engineering, v. 22, n. 2, p. 39-45, 1990.

SARKER, B. R. Some comparative and design aspects of series production systems. IIE Transactions, v. 16, p. 229-239, 1984.

SCHRAGENHEIM, E.; RONEN, B. Drum-bufferrope shop floor control. Production and Inventory Management Journal, third quarter, pp. 18-22, 1990. SMUNT, T. L.; PERKINS, W. C. Stochastic unpaced line design: review and further experimental results. Journal of Operations Management, v. 5, n. 3, p. 351-373, 1985.

$\mathrm{SO}, \mathrm{K}$. C. On the efficiency of unbalancing production lines. International Journal of Production Research, v. 27, n. 4, p. 717-729, 1989.

SPEARMAN, M. L.; WOODRUFF, D. L.; HOPP, W. J. CONWIP: a pull alternative to Kanban. International Journal of Production Research, v. 28, n. 5, p. 879-894, 1990.

TAKAHASHI, K.; NAKAMURA, N.; OHASHI, K. Order release in JIT production systems: a simulation study. Simulation, v. 66, n. 2, p. 75-87, 1996.

TAYUR, S. R. Structural properties and a heuristic for kanban-controlled serial lines. Management Science, v. 39, n. 11, p. 1347-1358, 1993.

THOMPSON Jr., W. W.; BURFORD, R. L. Some observations on the bowl phenomenon. International Journal of Production Research, v. 26, n. 8, p. 13671373, 1988.

WIGHT, O. Input/output control a real handle on lead time. Production and Inventory Management, v. 11, n. 3, p. 9-31, 1970.

\section{THE RELATIONSHIP BETWEEN PRODUCTION PLANNING AND CONTROL SYSTEMS AND METHODS OF CAPACITY ALLOCATION}

\section{Abstract}

There is a lack of researches on the relationship between methods of capacity allocation of manufacturing resources and production planning and control systems. Studies about capacity allocation are based on simplified push production systems not considering more current production management systems. By other side, studies about efficiency of production management systems don't consider the effect of different criteria of capacity allocation of manufacturing resources at the results. The purpose of this paper is to investigate how the different policies of capacity allocation and different production planning and control systems interrelate between each other.

Key words: capacities allocation, balanced production, unbalanced production, Kanban, CONWIP, drum-buffer-rope. 